\title{
AS EXPERİ̂NCIAS DE DOCENTzS DA EDUCAÇÃO BÁsICA DO RIO GRANDE DO SUL COM ALUNOS DA REDE PÚBLICA EM TEMPOS DE ENSINO REMOTO E PANDEMIA
}

\author{
THE EXPERIENCES OF BASIC EDUCATION TEACHERS OF \\ RIO GRANDE DO SUL AMONG PUBLIC EDUCATION STUDENTS \\ IN TIMES OF REMOTE EDUCATION AND PANDEMIC
}

\section{Lílian Carine Madureira Vieira da Silva}

Pós-Graduada em Psicopedagogia pela Pontifícia Universidade Católica do Rio Grande do Sul (Porto Alegre/Brasil). Mestranda no Programa de Mestrado Profissional em Educação pela Universidade Estadual do Rio Grande do Sul - Câmpus Litoral Norte (Osório/Brasil).

E-mail: lilianmad1@yahoo.com.br

\section{Khrysalis Pires de Castro}

Especialista em Educação Física Escolar e Educação pelo Instituto Federal de Educação Sul Rio Grandense (Sapucaia do Sul/Brasil). Mestranda no Programa de Mestrado Profissional em Educação pela Universidade Estadual do Rio Grande do Sul - Câmpus Litoral Norte (Osório/Brasil).

E-mail: khrysalis-castro@uergs.edu.br

\section{Rita Cristine Basso Soares Severo}

Doutora em Educação pela Universidade Federal do Rio Grande do Sul (Porto Alegre/Brasil).

Professora Adjunta da Universidade Estadual do Rio Grande do Sul (Osório/Brasil).

E-mail: rita-severo@uergs.edu.br

Recebido em: 20 de abril de 2021

Aprovado em: 6 de julho de 2021

Sistema de Avaliação: Double Blind Review

RPR |a. 18|n. 3 | p. 238-252 | set./dez. 2021

DOI: https://doi.org/10.25112/rpr.v3.2585 


\section{RESUMO}

Após um ano de pandemia causada pela Covid-19, os sujeitos que compõem a educação básica, docentes, discentes, famílias, ainda tentam se adaptar a esta nova realidade. Assim, neste artigo, propõe-se analisar os efeitos da pandemia diante da atual situação de trabalho dos docentes da educação básica da rede pública do Rio Grande do Sul. Para tanto foi feita entrevista estruturada com os profissionais que se voluntariaram a participar da pesquisa. As perguntas foram desenvolvidas a fim de responderem os nossos objetivos que são: compreender as experiências das professoras e professores frente ao ensino remoto durante a pandemia de Covid-19 e analisar as experiências de professores e professoras tensionando a formação docente e o currículo. Para tanto, utilizamos das lentes dos Estudos Culturais como ferramentas de análise dos fazeres e saberes da docência em tempos de pandemia e também no tensionamento do currículo escolar ante a atual situação vivida pela sociedade. Os resultados demonstram que o currículo, com seu modo de controle de espaço e tempo, não tem mais o mesmo alcance no espaço escolar e entre os alunos, evidenciando a incompatibilidade entre o ensino remoto e o currículo escolar tradicional. Desse modo, urge repensar a forma e as relações do ensino-aprendizagem na educação brasileira.

Palavras-chave: Docência. Currículo. Pandemia. Ensino remoto. Educação básica.

\section{ABSTRACT}

After a year of Covid-19 pandemic, the subjects that make up basic education, the teachers, students and families, still try to adapt to this new reality. Thus, in this article, it is proposed to analyze the effects of the pandemic in view of the current work situation of teachers of public basic education of Rio Grande do Sul state. For this purpose, a structured interview was carried out with the professionals who volunteered to participate in the research. The questions were developed in order to respond to our objectives, which are: to understand the experiences of teachers in face of remote teaching during Covid-19 pandemic and to analyze the experiences of teachers while tensioning teacher formation and the curriculum. For this purpose, we use Cultural Studies as tools for analyzing teaching practices and knowledge in times of pandemic and also the tensioning of the school curriculum in the face of the current situation experienced by society. The results demonstrate that the curriculum, and its way of controlling space and time, no longer has the same scope in the school space and among students, showing an incompatibility between remote education and the traditional school curriculum. Thus, there is an urgent need to rethink the form and relations of teaching and learning in Brazilian education.

Keywords: Teaching. Curriculum. Pandemic. Remote teaching. Basic education. 


\section{INTRODUÇão}

Em março de 2021 foi completado um ano da pandemia causada pela Covid-19, este episódio global trouxe muitas mudanças em todo o contexto social: fechamento de comércio e serviços não essenciais, trabalho remoto, home office, cuidados redobrados com higiene, uso de máscara para sair de casa etc.

O estado do Rio Grande do Sul, considerando as orientações da Organização Mundial da Saúde (OMS) quanto aos cuidados recomendados no enfrentamento da pandemia provocada pela Covid-19 manifestase através de decretos, entre eles o decreto n 55.128, de 19 de março de 2020, que declara estado de calamidade pública em todo o território estadual para fins de prevenção e de enfrentamento à epidemia causada pela Covid-19, e dá outras providências.

0 decreto estadual $n^{\circ}$ 55.240/2020, de 10 de maio de 2020, que institui o Sistema de Distanciamento Controlado para fins de prevenção e de enfrentamento à epidemia causada pelo novo Coronavírus (SarsCoV-2) no âmbito do Estado do Rio Grande do Sul, reitera a declaração de estado de calamidade pública em todo o território estadual e dá outras providências.

Considerando a Portaria Conjunta SES/SEDUC/RS n 01/2020, de 04 de junho de 2020, que dispõe sobre as medidas de prevenção, monitoramento e controle do vírus causador da Covid-19 a serem adotadas por todas as Instituições de Ensino no âmbito do Estado do Rio Grande do Sul, a área da educação não ficou de fora da mudança repentina, desde a educação básica até a superior, as aulas foram suspensas e tanto professores quanto estudantes e famílias tiveram que se adaptar em poucos dias ao novo modo de ensino.

Em 28 de abril de 2021, foi publicado o decreto 55.856 que possibilitou a volta ao ensino na modalidade híbrida em que os estudantes têm atividades presenciais na escola e também realizam atividades remotas. Com carga horária para o Ensino Fundamental de três horas presenciais e uma hora, remota. Com o avanço da vacinação de professores, cada vez mais escolas estão retomando o ensino presencial no estado, que segue não obrigatório.

Diante da situação de isolamento social os professores se viram desafiados a adaptarem-se ao Ensino Remoto Emergencial (ERE), a eles foi delegada a responsabilidade de elaboração de atividades além de eficazes, atrativas aos estudantes, principalmente os professores da educação básica, foco deste trabalho. Além disso, tiveram também que aprender a lidar com tecnologias desconhecidas e formatos de aulas inéditos, docentes da educação pública ainda contam com o desafio da falta de acesso à internet de muitos de seus alunos.

Diante da atual situação de trabalho dos docentes da educação básica pública questionamos: como estes profissionais estão lidando com a situação de aulas durante a pandemia? Como esta nomeada "era 
de imprevistos" da contemporaneidade vêm constituindo outros modos de fazer a docência na educação básica? Para responder a estas perguntas delineamos os seguintes objetivos, sendo o geral compreender as experiências das professoras e professores frente ao ensino remoto durante a pandemia de Covid-19 e, tendo como objetivo específico analisar as experiências de professores e professoras tensionando a formação docente e o currículo.

As análises serão feitas sob as lentes dos Estudos Culturais, analisando os fazeres e saberes da docência em tempos de pandemia e tensionando o currículo escolar com a atual situação vivida pela sociedade. 0 aporte teórico será em autores que tecem diálogos com as lentes dos Estudos Culturais como Veiga-Neto (2002), Hall (1997), Sacristán (2005) e Varela (1992). A opção por tomar este caminho de análise se dá por entendermos que o currículo brasileiro não possibilita flexibilidade, desta forma torna a adaptação ao novo cenário de ensino-aprendizagem mais penoso e demorado tanto aos docentes quanto aos estudantes e suas familias.

A fim de responder a estas perguntas e atingir nossos objetivos optamos por utilizar a entrevista estruturada com professores e professoras da educação básica da rede pública de ensino do estado do Rio Grande do Sul. Foram feitas perguntas direcionadas ao atual momento de trabalho pelo qual esses sujeitos estão vivenciando.

Iniciaremos o artigo contextualizando a doência e seus saberes e fazeres no contexto da pandemia, em seguida delimitamos e justificamos a metodologia escolhida para então analisarmos os dados levantados na entrevista, ali explanamos as preocupações e dificuldades encontradas ou não pelos voluntários desta pesquisa, analisamos suas falas e identificamos questões relacionadas às tensões provocadas pelo ensino remoto e o currículo tradicional. Após estas discussões seguimos para a conclusão do artigo, lá analisamos e apontamos a necessidade e urgência para que seja pensado um novo currículo escolar para um novo tempo, pois acreditamos que mesmo após a pandemia, as aulas não serão mais as mesmas.

Para dar início às discussões precisamos, antes de tudo, falar sobre o exercício da docência em tempos de pandemia.

\section{A DOCÊNCIA E SEUS SABERES E FAZERES NO CONTEXTO DA PANDEMIA}

Estamos imersos no contexto atual vivendo experiências que colocam em xeque os dispositivos pedagógicos que aprendemos a utilizar. A ordem que aprendemos a cultivar e a defender nos espaços e tempos escolares parece estar ruindo frente ao que estamos nomeando de "era dos imprevistos". Nesta "era" algo está "fora da ordem", que "borra a ordem", ou "atrapalha a ordem". "Ordem" no sentido de 
disposição regular e metódica. Quando se pensa em espaços e tempos escolares e práticas que neles se realizam, é possivel indagar: de que tipo de "ordem" estamos falando?

A pandemia causou, entre tantas outras coisas, mudanças profundas na escola contemporânea, uma delas foi colocar em suspenso o tempo e espaço da sala de aula. Tal suspensão provocou necessariamente os saberes e os fazeres da docência. Faz-se necessário refletir aqui sobre os conceitos de espaço e tempo. 0 espaço posto aqui é mais que o cenário em que acontecem as práticas dos jovens-alunos. 0 espaço faz parte da trama. As divisões que ocorrem na escola, a arquitetura das salas, os corredores, os muros, os lugares permitidos e não permitidos.

A mediação e o controle de tais espaços estão envolvidos em estreitas relações de poder. 0 tempo, neste estudo, assim como o espaço, também é entendido como algo não natural. São vistos como construções sociais, elementos inventados e reinventados pela nossa cultura e se transformam e transformam os sujeitos de formas diferentes, instituindo modos de ser e estar na cultura contemporânea.

A escola, entre os séculos $\mathrm{XV}$ e $\mathrm{XVI}$, foi se constituindo como um espaço singular para abrigar as gerações mais jovens. Institucionalizou-se e configurou-se tendo como função além de transmitir a cultura e os conhecimentos, também disciplinar as atitudes, ordenar e classificar os comportamentos, unificar linguagens. Coube à escola dosar os graus de liberdade, instituir a civilidade e a racionalidade com o objetivo de adaptar as gerações mais jovens às novas formas de configurações sociais. Essa função foi conferida à escola, a partir do ideário iluminista projetado na Modernidade (VARELA; ALVAREZ-URÍA, 1992).

Assim, a instituição escolar foi o dispositivo que se construiu para encerrar a infância e a adolescência. Encerrá-la, tanto do ponto de vista topológico ou corpóreo, quanto do ponto de vista de categorias que a pedagogia elaborou para construí-la. Ainda que a infância e a escola possam parecer existir desde sempre, e que a relação entre ambas possa parecer natural, as formas de percebê-las estiveram imbricadas no processo de constituição da Modernidade.

Ao analisar a escola, Veiga-Neto (2002), destaca que o currículo foi a grande maquinaria da escola moderna que rompeu com os sentidos de tempo e espaço medievais. "O currículo imprimiu uma ordem geométrica, reticular e disciplinar tanto aos saberes quanto à distribuição desses saberes ao longo de um tempo" (p. 164). Para o autor, em termos de tempo, o currículo produziu e, ainda produz rotinas e ritmos para todas as pessoas que, de alguma maneira, têm relação com a escola.

O tempo na escola é minuciosamente calculado, com horários específicos para cada disciplina, recreio, entrada e saída. Em termos mais amplos, o tempo é distribuído, na maioria das escolas, por séries de durações anuais, com progressivo aumento no grau das exigências. Para a maior produtividade do tempo, 
é preciso que os corpos não estejam dispersos no espaço, e sim submetidos a algum tipo de cerceamento ou confinamento.

Nessa mesma direção, propõe Sacristán (2005) que cada atividade que desenvolvemos na escola, tais como, ler, escrever, resumir, memorizar, resolver problemas, desenhar, realizar um exercício de ginástica, representam formas de utilizar o espaço e o tempo. Uma vez fixadas, as sequências das tarefas nas organizações escolares, serão responsáveis por manter o ordenamento nos espaços e tempos das salas de aulas. $O$ espaço escolar foi sendo modelado para que nele tenham lugar determinados acontecimentos, para realizar algumas atividades ou levar um estilo de vida específico.

Sugere ainda, o autor, que o espaço não é só uma realidade física de algumas dimensões em que é possível realizar algumas atividades. 0 espaço representa algo para nós: não é neutro, nos afeta e envolve, é um âmbito em que nossa experiência fica associada. 0 espaço não é indiferente para nós, nos afeta por sua presença e aspecto, pelo estado de ânimo que propicia, pela satisfação que produzem em nós as atividades realizadas nele, pelo estilo de vida que permite. Os espaços escolares são espaços regulados com sua própria disposição interna, contêm determinações normativas, regras de comportamentos para se desenvolver neles que indicam o que é certo fazer e o que não se deve fazer. Como então considerar o espaço virtual em sala de aula?

Frente a essas considerações ingressar em uma nova fronteira, a do mundo virtual. Em plena era da tecnologia da informação, a educação, de maneira especial, vive esse momento de transição, provocado pelo estado pandêmico. Aos poucos, a sala de aula virtual vai ganhando forma, o sistema de aprendizagem vai se otimizando e os protagonistas desse processo, professores, professoras e estudantes vão se modificando e constituindo novas relações de ensino e aprendizagem.

\section{TRAJETÓRIAS METODOLÓGICAS}

Este artigo é um recorte de uma pesquisa realizada pela linha 1 de pesquisa em currículos e políticas na formação de professores do Mestrado Profissional em Educação da Universidade Estadual do Rio Grande do Sul - UERGS. A pesquisa tem o caráter qualitativo e utiliza-se de uma entrevista estruturada, já que as perguntas seguiram um roteiro fixo específico (GIL, 2002) para compreender as experiências das professoras e professores frente ao ensino remoto durante a pandemia de Covid-19.

Utilizamos uma aproximação com os Estudos Culturais para tensionar a formação docente através das experiências relatadas pela entrevista estruturada. Esta entrevista foi formatada no Google Forms e encaminhada para professoras e professores da rede pública de ensino pelo aplicativo Whatsapp devido ao cumprimento do distanciamento físico exigido. 
Para delimitar a amostragem e definir a população deste estudo, utilizou-se da denominada amostragem intencional aleatória pois seleciona um determinado número aleatoriamente (GRAY, 2012), portanto utilizou-se de professoras e professores da rede pública de ensino dos quais as pesquisadoras possuíam contato. Estas entrevistas ocorreram no mês de março de 2021. A análise dos dados ocorreu a partir da interpretação das respostas desses docentes utilizando o método de análise de conteúdo de Bardin (1977).

\section{RESULTADOS E ANÁLISE}

Para o Google Forms foram desenvolvidas as seguintes perguntas: "Quanto tempo atua na docência?"; "Quais os desafios da docência no espaço virtual?"; "Como é pensado metodologicamente as suas aulas remotas?"; "Como se dá a sua relação com os estudantes nos espaços virtuais?", além de idade, gênero e etnia. A condição para responder ao questionário foi a de trabalhar na educação básica da rede pública de ensino.

Um total de 38 docentes, sendo 37 mulheres e um homem, participaram da pesquisa de forma voluntária. As perguntas foram escolhidas com o intuito de fomentar esta pesquisa, trazendo dados relevantes para serem analisados a respeito da atual condição de trabalho desses profissionais.

Para realizar a investigação dessas informações, optamos por uma análise a partir das unidades de registro e conteúdos através da recorrência e frequência das respostas dessas professoras e professor, buscando compreender ou não as experiências das professoras e professor frente ao ensino remoto durante a pandemia de Covid-19. A análise de conteúdo é entendida por Bardin (1977) como uma técnica de investigação que tem por finalidade a descrição objetiva, sistemática e quantitativa de um conteúdo, que neste caso, está sendo comunicado a partir das entrevistas estruturadas.

A análise de conteúdo possui três etapas sendo elas: a pré-análise, a exploração do material e o tratamento dos resultados.

1) Pré-análise: organização do material de estudo, como escolha dos sujeitos da pesquisa, formulação do roteiro de pesquisa para análise e formulação de objetivos.

2) Exploração do material: leitura e agrupamento das respostas da entrevista estruturada realizada no Google Forms.

3) Tratamento dos resultados: foram definidas unidades de registro para cada uma das unidades de contexto.

A partir desta análise, para a interpretação desses dados, dividimos em duas categorias que serão discutidas adiante. 


\subsection{DAS PAREDES DE CONCRETO DA SALA DE AULA TRADICIONAL PARA AS PAREDES DE TELA DO GOOGLE MEET, WHATSAPPE YOUTUBE}

As professoras e professor voluntários, ao serem questionados sobre como eram pensadas metodologicamente as suas aulas remotas, demonstraram, em sua grande maioria, preocupação em planejar as aulas de forma a manter o interesse de seus alunos e alunas. Mais especificamente, de 38 participantes, 16 mencionaram esta prioridade em seu planejamento.

Nesta direção, para pensar em prática docente, torna-se importante pensar no currículo escolar. Para Veiga-Neto (2002, p.164) "Em termos temporais, o currículo engendrou - e de certo modo ainda engendra - rotinas e ritmos para a vida cotidiana de todos aqueles que, direta ou indiretamente, têm algo a ver com a escola", esta função temporal do currículo foi uma das maiores dificuldades para discentes e docentes no contexto de pandemia em que vivemos.

A rotina escolar foi alterada e reformulada e, para atender as necessidades educacionais de todos e todas, foi preciso reinventar uma nova rotina escolar. Além disso, docentes encontram-se sobrecarregados quando, por exemplo, as fronteiras de trabalhos se borram e trabalho doméstico e docente se cruzam dentro de uma rede de afazeres realizados dentro de casa e outras dificuldades encontradas para a prática docente em contexto pandêmico, como foi apontado nas respostas das professoras voluntárias.

Ainda pensando a partir dos termos que Veiga-Neto (2002) propõe, ao pensar no currículo, que os termos espaciais delimitam os limites onde o "outro" passa a existir e essa diferença passa a ser um "problema". Quando partimos para a constituição desse "outro" no sentido de aprendizagem encontramos uma grande diferença que antes estava "ocultada" em uma ideia de educação para todos.

Questionamos, o currículo único e universal é pensando para quem? Em um ensino remoto emergencial ficou evidenciado que o acesso à educação não contempla a todos; os docentes têm incessantemente buscado formas para atender a maioria desses sujeitos, possibilitando, de diversas formas, o acesso a materiais para seus estudantes, esse movimento é identificado nas respostas das professoras e professor voluntários.

Nesse sentido, as tecnologias funcionam como uma aliada a essa situação emergencial como uma mudança de metodologias devido ao imprevisto da pandemia. Os modos de se fazer educação está levantando questionamentos por parte dos docentes e da comunidade escolar sobre as formas 
institucionais que se utilizam de sistemas educacionais tradicionais e isto pode estar possibilitando pensar novas formas de representações dos papéis dos docentes e discentes (LÉVY, 2005).

Em algumas respostas podemos observar o emprego da tecnologia como uma ferramenta utilizada com a metodologia tradicional. Importante ressaltar que, em uma abordagem tradicional, a realidade que é objeto de conhecimento, é cumulativo e deve ser adquirido por uma "transmissão" desses conteúdos propostos na instituição escolar (MIZUKAMI, 1986).

Gravo vídeos explicando o conteúdo para enviar junto com a atividade, que são postadas no Google Sala de Aula. Posteriormente, faço aula no Google Meet para corrigir e explicar novamente o conteúdo..." (D2).

Tento explicar a atividade escrevendo como se estivesse falando com eles, mesmo assim utilizo vídeos e as aulas síncronas para esclarecer as dúvidas. Então slides, vídeos e vídeos ao vivo. (D16).

Nesses dois trechos percebe-se a ideia da educação onde o docente "transmite" o seu conhecimento. Apesar do espaço não ser o de uma sala de aula tradicional, esses dois relatos dão a ideia de que as tecnologias foram incluídas (pelos vídeos, google meet, google sala de aula), mas ainda foca-se no professor e professora como detentores desses conhecimentos que, em um ambiente virtual com acesso à internet, poderiam e podem, por exemplo, tornar-se um "copia e cola".

Esse desenvolvimento tecnológico traz elementos para (re)pensarmos os processos educacionais tradicionais, mas sem esquecer a articulação necessária entre ensino e aprendizagem, e isso significa ter clareza de que ensinar é um processo totalmente diferente de educar. 0 ensino sem a aprendizagem vira um processo inócuo, vazio. Por isso, faz-se necessário que as tecnologias sejam inseridas no planejamento pedagógico com um propósito educacional claro e que seja significativo aos sujeitos envolvidos. Não pode ser algo atropelado, feito de forma aligeirada para atender demandas de cumprimento de currículo. (GOEDERT; ARNDT, 2020, p. 108-109).

Em contrapartida podemos observar nas narrativas abaixo que alguns docentes, em sua metodologia, buscam construir aprendizados pensados nas individualidades, onde os estudantes podem refletir a respeito e recriar formas de ser e estar no mundo, utilizando os conhecimentos já existentes e produzindo

\footnotetext{
1 Para manter em sigilo a identidade dos voluntários e voluntárias, optou-se por utilizar a letra "D" para docente e a numeração, que foi designada a cada resposta, na ordem em que os voluntários e voluntárias respondiam.
} 
aprendizagens significativas para a comunidade em que vivem e que fogem da proposta metodológica de ensino tradicional:

Conhecer a realidade do estudante, para a partir dessa realidade construir propostas interativas que promovam a aprendizagem respeitando o tempo e os espaços de cada criança, na sua individualidade. (D14).

Ensinar a partir do que o aluno tem a sua volta e ir além disso para aprender a questionar, pensar e responder fora de um modelo pronto. (D15).

A possibilidade de reinventar as práticas docentes em novos espaços está sendo um desafio tanto para docentes quanto para discentes. Em um momento em que a educação básica muda os seus espaços, as perspectivas mudam e esse movimento implica na dissolução das fronteiras das formas tradicionais de ensino que pouco tem a ver com a reinvenção de novos espaços e formas de vivenciar estes espaços (VEIGA-NETO, 2002).

Desta forma passa a se considerar o que Veiga-Neto (2002) define como "Iugarização", capacidade de mudar de lugares e criar lugares. É a mobilidade e a possibilidade de reinventar-se em diferentes lugares, tanto físicos como simbólicos (VEIGA-NETO, 2002).

Nessa direção o entendimento de cultura, como um conjunto de representações, se faz perceptível, já que essas representações manifestam-se nas imagens, narrativas, artefatos e são produzidas através das relações sociais onde existem uma ordem de poder imposta. Para Hall (1997, p. 33), "a cultura é uma das condições constitutivas de existência de toda prática social e toda prática social tem uma dimensão cultural. Não que não haja nada além do discurso, mas que toda prática social tem o seu caráter discursivo". E isto reflete no currículo escolar, toda essa ordem social e relações de poder também compõem o ambiente escolar, através dos currículos, e isso reflete nas práticas docentes tornando os desafios muito maiores frente ao "imprevisto" como analisaremos mais adiante.

\subsection{DESAFIOS DA DOCÊNCIA FRENTE AO IMPREVISTO}

Entre os dados levantados na pesquisa é notável a questão do despreparo curricular das escolas frente a esta nova modalidade de ensino. Da forma que foi pensado e construído, ele não é suficiente nem eficiente neste momento. Fazemos esta observação baseadas em Veiga-Neto (2002), ao afirmar que:

O currículo é pensado e funciona como uma estrutura classificatório disciplinar; por isso ele é um estruturante. $E$, por ter uma estrutura disciplinar, ele funciona como um estruturante disciplinador. (VEIGA-NETO, 2002, p. 171). 
Podemos entender que, de certa forma, o currículo, no ensino remoto, perde essa função estruturante e disciplinadora já que a modalidade de ensino foi modificada. Não há como disciplinar os corpos, não há mais o controle do tempo e do espaço. Tal constatação fica evidente ao analisarmos as falas dos voluntários que participaram da pesquisa.

Ao serem questionados a respeito dos desafios da docência em espaço virtual, os docentes mantiveram certa unidade em suas respostas em relação à primeira pergunta. Dos 38 voluntários, 13 responderam que o maior desafio era o de manter o interesse de seus alunos e alunas nas aulas e 14 afirmaram que 0 desafio era alcançar os estudantes com dificuldade de acesso ao sinal de internet:

Principalmente a disponibilidade de internet e computador ou celular por parte dos alunos. Muitas famílias não têm condições de ter esse material, o que dificulta muito o ensino remoto. (D8).

\section{Muitos... [desafios]}

-A interação.

-As dificuldades de acesso dos Estudantes.

-Motivar os alunos com as propostas.

-Ensinar de forma remota, em um tempo em que o mundo passa por uma pandemia,que tem atingido a todos de alguma forma é um esforço diário de muita determinação, resiliência e comprometimento. (D 14).

O desafio de manter $\mathrm{o}$ interesse de alunos e alunas em aulas que fogem do tradicional é um desafio curricular não só da escola, mas dos próprios cursos superiores de licenciatura. Muitos professores não tiveram acesso à disciplinas ligadas às Tecnologias Digitais de Informação e Comunicação (TDIC) em suas graduações e se viram obrigados, repentinamente, a pensarem em toda uma nova metodologia para alcançar o interesse dos estudantes e os objetivos das aulas. Vale ressaltar: não é culpa de professoras e professores da educação básica o engessamento curricular que vivenciamos em todo o país.

Tal fato não exclui professores e professoras a respeito da alfabetização digital, o que acontece é que não houve estudos e capacitação dessas pessoas para o formato de ensino remoto e esta mudança radical em sua forma de trabalho ocorreu em questão de dias. Sobre alfabetização digital, Tarouco (2019) explana:

A alfabetização digital pressupõe apenas habilidades básicas para o uso de computadores e da Internet. As pessoas que evidenciam tais habilidades usam, tipicamente, os recursos das tecnologias de informação e comunicação (TIC) na qualidade de consumidores, ficando a autoria ou a produção de informação confinada à geração de comunicação interpessoal (correio eletrônico, mensagens instantâneas, etc.). (TAROUCO, p. 34, 2019). 
É evidente que esta é uma preocupação muito válida já que:

No contexto atual, da chamada sociedade da informação, a alfabetização digital é um dos pontos mais críticos no processo de inclusão digital. Ela está relacionada à aquisição de habilidades básicas para o uso de computadores e da Internet. (TAROUCO, p. 33, 2019).

O atual cenário evidencia mais um dado que é preocupante: a falta de acesso à internet, principalmente para estudantes que residem nas áreas periféricas das cidades. Como a alfabetização digital poderá ser uma realidade se nem sinal de internet essas famílias têm em suas casas? Como manter o interesse de alunos dos anos iniciais em aulas pelo celular e com sinal fraco? Só professores e professoras da educação básica sabem a dimensão deste desafio.

Vale ressaltar que

[...] é importante considerar as fragilidades e desigualdades estruturais da sociedade brasileira que agravam o cenário decorrente da pandemia em nosso país, em particular na educação, se observarmos as diferenças de proficiência, alfabetização e taxa líquida de matrícula relacionados a fatores socioeconômicos e étnico-raciais. Também, como parte desta desigualdade estrutural, cabe registrar as diferenças existentes em relação às condições de acesso ao mundo digital por parte dos estudantes e de suas famílias. (BRASIL, 2020, p. 3).

Ou seja, o cenário pandêmico escancarou as desigualdades de acesso à educação em nosso país. Somando mais um obstáculo no enfrentamento das desigualdades sociais. Logo, além de um currículo escolar que não dá às professoras e aos professores ferramentas necessárias de enfrentamento e adaptação à modalidade da aula remota, este mostra que não é eficiente diante de uma situação de crise. A realidade pandêmica é inédita na atualidade e no mundo inteiro, mas a dificuldade de adaptação curricular é um marco de seu engessamento.

Mais uma vez ressaltamos, esta não é uma falha dos docentes. Quase todos os voluntários da pesquisa relataram, em algum momento da entrevista, sua preocupação para com os estudantes que precisam atender e acolher. Este se torna um grande desafio:

Principalmente não saber como o outro se comporta. Não saber se realmente entendeu o conteúdo, se gostou da aula. Conhecer o método de aprendizado do aluno também é difícil. (D3).

O voluntário D5, traz um apanhado geral da realidade dos docentes da educação básica: 
O principal desafio é atingir todos os estudantes, visto que a desigualdade impera em nosso país, ainda que todos tenham acesso de alguma forma, nem todos conseguem desenvolver todas as atividades com o desempenho esperado. Outro desafio é planejar para estudantes que não conhecemos, pois na Educação Básica há diferentes realidades, quando planejamos, mesmo no espaço virtual, para aqueles estudantes que já conhecemos, conseguimos individualizar o atendimento, mas para os alunos novos no espaço virtual isso é mais difícil... é necessário o apoio familiar e isso é bem mais difícil quando se trata de adolescentes, que é o meu caso. Ainda tem a questão das dificuldades dos professores com as tecnologias, o que não é o meu caso enquanto professora, mas vejo com relação aos colegas e também com os professores de minhas filhas, situações em que os professores não sabem planejar para o ambiente virtual e apenas transferem o suporte físico para o suporte digital e mantêm a mesma metodologia, exigindo cópias nos cadernos. (D5).

Apesar de não ter mencionado diretamente, D5 nos mostra as falhas curriculares na formação de professores e no suporte ao ensino remoto. Já completamos um ano e meio nessa modalidade de ensino, esta pesquisa foi feita no início do mês de março de 2021, essa falta já poderia ter sido suprimida. No entanto, segue sendo realidade na vida de muitos profissionais.

\section{CONSIDERAÇÕES FINAIS}

Os desafios encontrados pela comunidade escolar frente à pandemia acarretada pela Covid-19 proporcionaram muitas incertezas quanto aos métodos de ensino e papéis de docentes e estudantes. Durante um ano e meio na busca em atender a proposta de isolamento social para conter a disseminação do vírus, podemos verificar nas respostas das professoras e professor voluntários as suas preocupações, receios e principalmente o surgimento e a necessidade de novas possibilidades do fazer docente.

Notamos docentes da rede pública de ensino que, apesar de sobrecarregados, seguem resilientes; que apesar dos novos obstáculos e falta de apoio no sentido de treinamento e acesso dos estudantes às novas tecnologias, ainda se preocupam em fazer a palavra chegar a eles.

Mesmo com o engessamento curricular e a ordem imposta dentro da organização desses currículos, percebemos a necessidade de pensar o papel da docência e a possibilidade de repensar suas práticas a partir destes imprevistos, onde o modelo de educação tradicional pouco proporciona outros modos de ser e estar dentro desses novos espaços.

A educação mudou, isso está claro. Essa mudança não ocorreu de forma vertical no sentido de ser uma nova imposição curricular, não veio de cima, esta não é uma nova forma de controle de tempo e espaços. 0 currículo, de fato, perdeu seu poder de controlar corpos e comportamentos. 
Não há como vigiar os estudantes, não há como disciplinar seus modos de ser, não há como disciplinar e podar suas identidades. Até o controle do tempo escorreu entre os dedos do currículo, é o estudante quem decide quando assistirá as aulas, já que elas, em sua maioria, são gravadas. Os estudantes decidem se ligam suas câmeras e microfones durante as aulas síncronas, tornando difícil, inclusive, a criação de vínculos afetivos entre professores e colegas de turma.

De forma inédita, o discente passou a ter controle de muitos aspectos na forma em que o ensino é "transmitido". Aos professores restou aprenderem a lidar com esses novos tempos na educação, novos tempos que não irão embora tão cedo, novos tempos que, como tudo indica, chegaram para ficar.

Como serão as voltas às aulas presenciais? Será possivel, ou melhor, será querida a reformulação de nosso currículo tão tradicional, tão controlador, tão sem representação? Será que a pandemia trouxe uma oportunidade para "tirarmos o gesso" do currículo escolar? São questionamentos sobre os quais ainda precisaremos refletir e tensionar.

\section{REFERÊNCIAS}

BARDIN, Laurence. Análise de conteúdo. Lisboa: Edições 70, 1977.

BRASIL. Ministério da Educação. Conselho Nacional de Educação. Conselho Pleno. Parecer CNE/CP nº 5/2020. Brasília, 2020.

. Decreto n 55.128, de 19 de março de 2020.

. Decreto $\mathrm{n}^{\circ}$ 55.240, de 10 de maio de 2020.

Decreto n 55.856, de 28 de abril de 2021.

. Secretaria da Saúde. Portaria Conjunta SES/SEDUC/RS n 01/2020, de 04 de junho de 2020.

GIL, C. A. Como elaborar projetos de pesquisa. 4. ed. São Paulo: Atlas, 2002.

GOEDERT, L.; ARNDT, K. B. F. Mediação Pedagógica e Educação Mediada por Tecnologias Digitais em tempos de pandemia. Criar Educação, Criciúma, v. 9, n² 2, Edição Especial 2020. - PPGE - UNESC.

GRAY, D. E. Pesquisa no mundo real. Tradução: Roberto Cataldo Costa, 2. ed. Porto Alegre: Penso Editora, 2012. 
HALL, Stuart. A centralidade da cultura: Notas sobre as revoluções culturais do nosso tempo. Educação \& Realidade, Porto Alegre, jul.- dez. 1997, vol. 22, n² 2, p. 17-46.

LÉVY, Pierre. Cibercultura. São Paulo: Editora 34, 2000.

MIZUKAMI, M. G. N. Ensino: as abordagens do processo. São Paulo: EPU, 1986.

SACRISTÁN, José Gimeno. 0 aluno como invenção. Porto Alegre: Artmed, 2005.

TAROUCO, Liane Margarida Rockenbach. Competências Digitais dos Professores. In: COMITÊ GESTOR DA INTERNET NO BRASIL (CGI.br). Pesquisa sobre o uso das tecnologias de informação e comunicação nas escolas brasileiras: TIC educação 2018. São Paulo: Comitê Gestor da Internet no Brasil, 2019. Disponivel em: https://cetic.br/media/docs/publicacoes/216410120191105/tic_edu_2018_livro_ eletronico. pdf. Acesso em: 16 março 2021.

VARELA, Julia; ALVAREZ-URÍA, Fernando. A maquinaria escolar. Teoria \& Educação, Porto Alegre, no 6, 1992.

VEIGA-NETO, Alfredo. De geometrias, currículo e diferenças. Educação \& Sociedade, ano XXIII, no 79, agosto/2002.

. Currículo, cultura e sociedade. Educação Unisinos, vol. 5, no 9, jul./dez. 2004. 